\title{
The Relationship Between Basipetal Auxin Transport and Calcium Allocation in Vegetative and Reproductive Flushes in Avocado
}

\author{
J.G.M. CUTTING* and J.P. BOWER**
}

Citrus and Subtropical Fruit Research Institute, P/Bag X11208, Nelspruit, 1200 (South Africa)

(Accepted for publication 18 May 1989)

\begin{abstract}
Cutting, J.G.M. and Bower, J.P., 1989. The relationship between basipetal auxin transport and calcium allocation in vegetative and reproductive flushes in avocado. Scientia Hortic., 41: 2734 .

Indole-3-acetic acid (IAA) export and ${ }^{45} \mathrm{Ca}$ uptake by excised avocado flower, fruitlet and shoots from the vegetative flush were determined in conditions which limited transpiration flow to a minimum. Treatments using auxin transport inhibitors were included to ascertain if IAA played a role in the allocation of $\mathrm{Ca}$. IAA levels were determined using radioimmunoassay. IAA export and ${ }^{45} \mathrm{Ca}$ uptake were strongest for the vegetative flush and weaker for the reproductive structures for the first 5 weeks after flowering. The competition for and control of Ca partitioning is discussed.
\end{abstract}

Keywords: avocado; calcium; IAA; partitioning, radioimmunoassay.

Abbreviations: $\mathrm{DPM}=$ disintegrations per minute; $\mathrm{IAA}=$ indole- 3 -acetic acid; $\mathrm{RIA}=$ radioimmunoassay; $\mathrm{TIBA}=2,3,5$ triiodobenzoic acid.

\section{INTRODUCTION}

The South African avocado industry is heavily dependent on exports of refrigerated fruits by air and sea to the northern hemisphere. Exports by sea involve road and sea journeys of $>10000 \mathrm{~km}$ at a temperature of $\sim 5.5^{\circ} \mathrm{C}$, and an interval of $\sim 4$ weeks from harvest to disembarkation in Europe. Fruit quality problems are magnified by this extended post-harvest period (Cutting et al., 1988).

Bower (1985) found that avocado fruits with a low Ca level had a greater

\footnotetext{
*Present address: Department of Horticulture, University of Stellenbosch, Stellenbosch, 7600, South Africa.

**Present address: South African Co-operative Citrus Exchange, P.O. Box 28, Nelspruit 1200, South Africa.
} 
potential for physiological disorders and poor post-harvest quality. Low levels of $\mathrm{Ca}$ in avocado fruits have been associated with rapid softening after harvest (Wills and Tirmazi, 1982) and with susceptibility to chilling injury (Chaplin and Scott, 1980). The avocado appears to have a very limited ability to take up Ca from orchard sprays (Veldman, 1983) or dipping solutions (Tingwa and Young, 1974). Eaks (1985) observed that the benefits of vacuum infusion of Ca were negated by the adverse effect on external quality when ripened after storage.

In general, it is agreed that Ca-related disorders arise from its internal distribution problems and its allocation between mature and growing regions of the plant (Bangerth, 1979; Marschner, 1983). It is usually accepted that transport of Ca occurs mainly in the xylem vessels and in Ca exchange sites along xylem walls (Hanson, 1984). Plants have to be continuously supplied with $\mathrm{Ca}$ as little or no redistribution occurs to new growth zones after accumulation in one site (Poovaiah, 1985). Competition between sinks is intensified when the calcium content in xylem sap is low and transpiration great (Clarkson, 1984). Other studies have, however, shown this relationship not to be so simple. For example, the influx of $\mathrm{Ca}$ in leaves declines after maturity, even though a constant transpiration rate is maintained (Koontz and Foote, 1966). It would therefore appear that plants have additional or alternative mechanisms of regulating their Ca distribution besides its strong relationship to water supply and movement in the xylem.

There is considerable evidence that auxin (indole-3-acetic acid, IAA) transport plays an important role in Ca allocation to developing tissues (Banuelos et al., 1987). The application of auxin transport inhibitors such as 2,3,5 triiodobenzoic acid (TIBA) led to Ca-related deficiency disorders in tomatoes and apples (Bangerth, 1973, 1976). Whitney et al. (1986) found that avocado fruits on trees with reduced vegetative vigour accumulated more $\mathrm{Ca}$. In the present paper, the relationship between vegetative and reproductive flushing, auxin export, sink strength for $\mathrm{Ca}$ and its allocation during flowering and early fruit growth of cultivar 'Fuerte' avocados will be discussed.

\section{MATERIALS AND METHODS}

General. - Flower and vegetative flushes of the 'Fuerte' avocado were removed from our orchard during August and September, 1988. All experiments were conducted in replications of three or four with 10 plant parts (flowers or vegetative flushes) per replication. All results are presented as the means of the replicates. All of the results were subjected to analysis of variance, and treatment comparisons were made using the Student-Newmans-Keuls comparison test, Duncans' new multiple range test and the Tukey comparison test. The comparison which gave the strictest test is that presented in the results.

TIBA in lanolin with 'Tween 20' was used to inhibit auxin transport. It was 


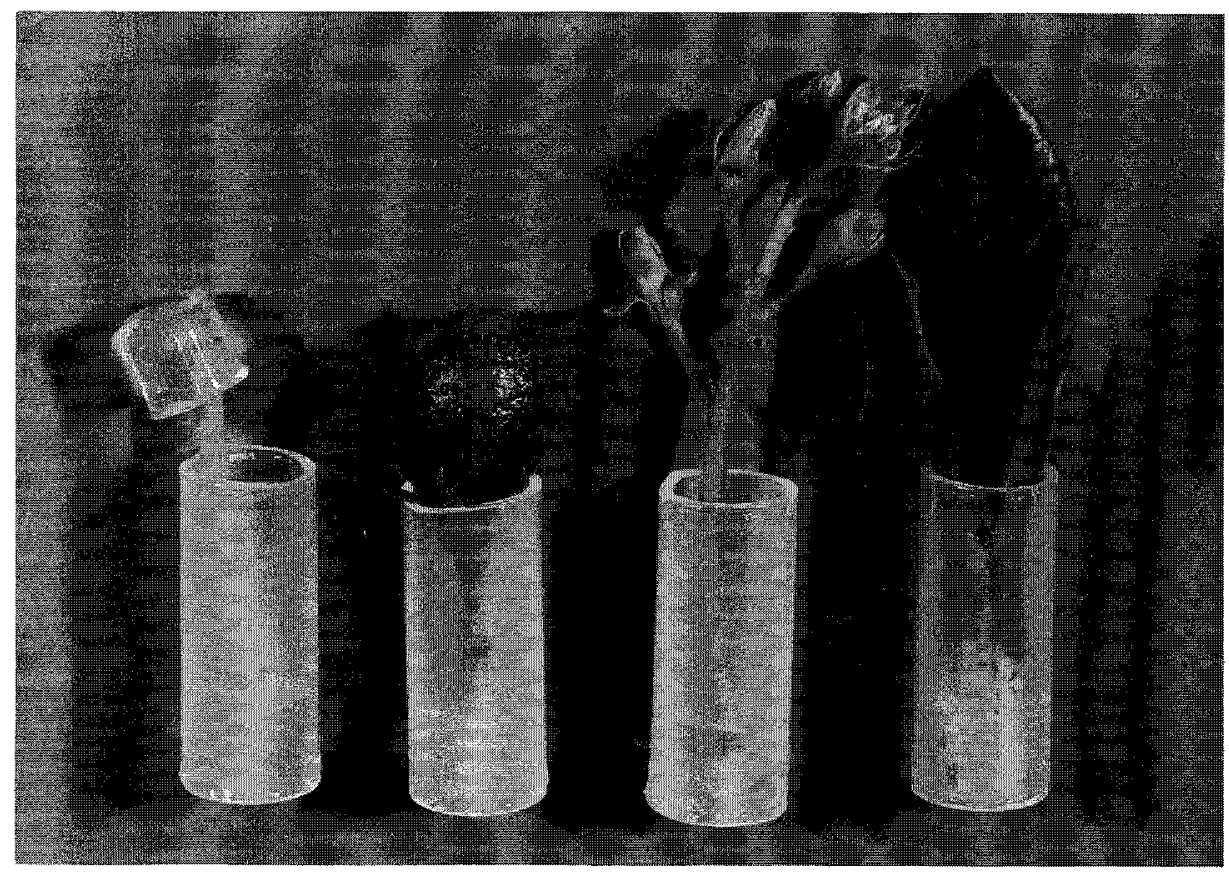

Fig. 1. The method used for determining IAA export and ${ }^{45} \mathrm{Ca}$ uptake. The agar blocks in the base of the modified tube are assayed for IAA. The top agar block, fruitlet, flowers or vegetative shoot were ashed for Ca determination (magnification $\times 3$ ).

applied to the base of the newly emerging vegetative flush or the expanding flower panicle $48 \mathrm{~h}$ prior to removal from the tree. The different plant parts (with or without TIBA, depending on treatment) were placed on $0.5 \mathrm{ml} 1.5 \%$ agar in a specially modified low-absorption (Nunc 466982 ) polyethylene tube (Fig. 1). The excised plant parts were then placed in a container with $100 \%$ $\mathrm{RH}$, together with small containers of $\mathrm{KOH}$ crystals (to remove $\mathrm{CO}_{2}$ ) and potassium permanganate (to remove ethylene) and left for $48 \mathrm{~h}$ in a $12-\mathrm{h}$ light: 12 -h dark cycle.

Determination of rate of basipetal auxin transport. - Flower peduncles, $25 \mathrm{~mm}$ long with the flowers removed, were individually placed on an agar block. Agar blocks with IAA concentrations from 0 to $1250 \mathrm{ng}$ were then placed on top of the peduncle and placed in the respective containers. After $48 \mathrm{~h}$ the bottom agar block was assayed for IAA content using a standard radioimmunoassay (RIA) procedure (Cutting et al., 1986). The antiserum characteristics were essentially the same as those reported by Weiler (1981). The experiment was repeated as above using TIBA. 
Determination of Ca uptake. $-{ }^{45} \mathrm{CaCl}$ [ $\sim 90000$ disintegrations per minute (DPM) ] was incorporated in agar blocks which were used as the bottom agar blocks and the experiment was conducted as above, but using the following treatment differences. Treatments with $1250 \mathrm{ng}$ IAA in the top agar block as well as flower, vegetative and young fruit material, both with and without TIBA, were used. The experiment was repeated twice. IAA was determined in the agar using RIA.

The method of Banuelos et al. (1987) was used for the determination of radioactive ${ }^{45} \mathrm{Ca}$. The flowers and vegetative flushes were ashed for $60 \mathrm{~min}$ at $550^{\circ} \mathrm{C}$ and dissolved in $2 \mathrm{ml} 2 \mathrm{M} \mathrm{HCl}$. A $0.1 \mathrm{ml}$ sample was then added to $5 \mathrm{ml}$ liquid scintillant and the radioactivity counted. Radioactivity determinations were made in triplicate.

Comparison of auxin export from vegetative and reproductive structures. - Portions of flower panicles containing 6-8 flowers (approximately one-tenth of the total flower panicle) and single vegetative flushes from the centre of the flower-panicle (Fig. 2) were placed on agar blocks and left for $48 \mathrm{~h}$ as above. The experiment was repeated five times from just prior to flower opening to when the fruit had reached $\sim 30 \mathrm{~mm}$. All the experiments included TIBA treatments. The diffused IAA content in the agar was determined using RIA.

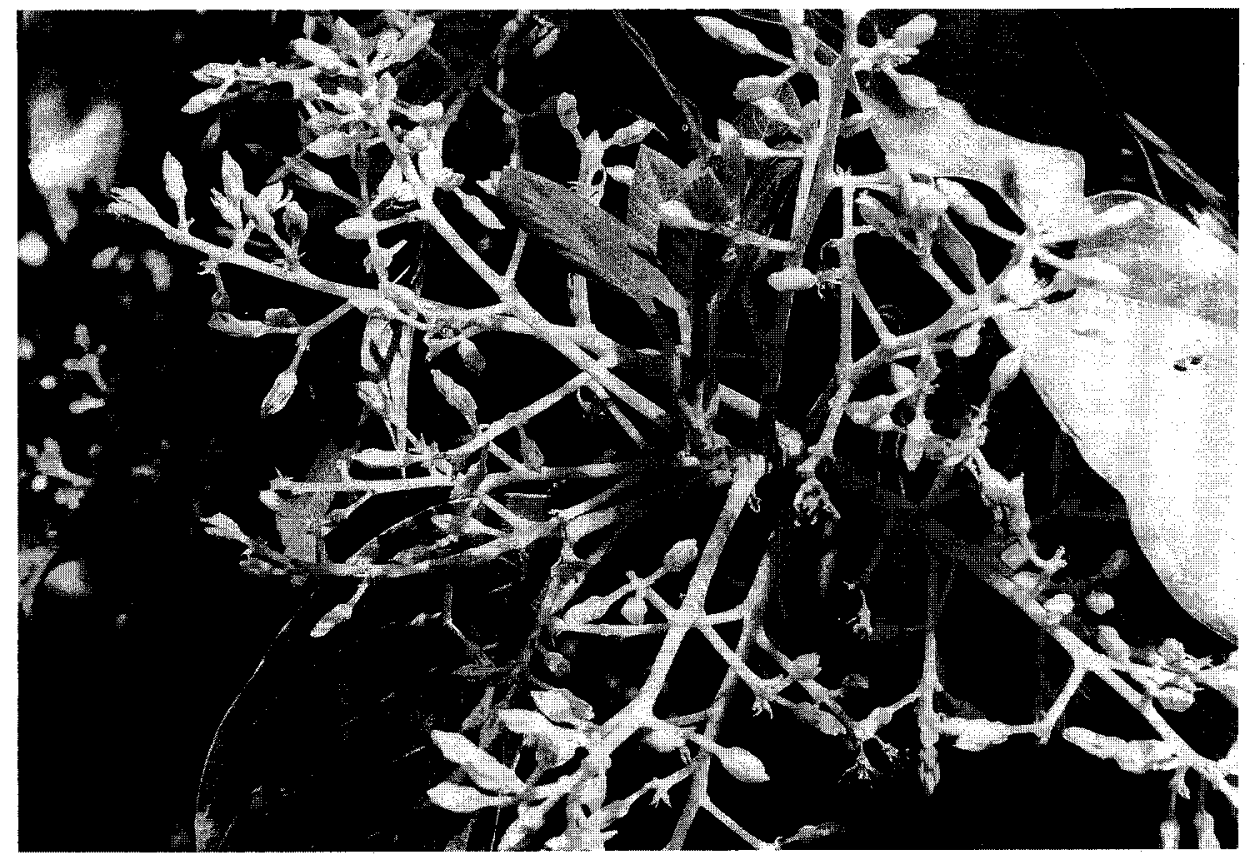

Fig. 2. Avocado flowering and early fruit set showing the newly emerging vegetative flush in the centre of the panicle. 


\section{RESULTS}

Rate of auxin transport. - Basipetal auxin transport into the agar increased in response to the increasing auxin concentration in the donor agar block (Table 1 ). The quantity of extractable IAA in the $25-\mathrm{mm}$ flower peduncle was almost the same as the amount of diffusable IAA from the control (zero IAA in the top agar block). Treatment with TIBA reduced the amount of IAA in the receiver blocks significantly.

Calcium uptake in response to basipetal auxin transport. - The uptake of ${ }^{45} \mathrm{Ca}$ was dependent upon the type of plant structure. The flower panicle took up $24 \%$, the vegetative flush $35-47 \%$ and the fruitlets $19-21 \%$ of the available ${ }^{45} \mathrm{Ca}$ (Table 2). In all cases, treatment with TIBA reduced Ca uptake.

\section{TABLE 1}

Diffusable IAA concentration in $\mathrm{ng}$ per 10 peduncles in receiver blocks of agar in response to different concentrations of IAA in the donor blocks and TIBA treatment

\begin{tabular}{llll}
\hline $\begin{array}{l}\text { IAA concentration in } \\
\text { donor block }(\mathrm{ng})\end{array}$ & 0 TIBA & TIBA & $\begin{array}{l}\text { Extractable IAA } \\
\text { in peduncle }\end{array}$ \\
\hline 0 (control) & $18.6^{\mathrm{a}}$ & $14.7^{\mathrm{a}}$ & $25.2^{\mathrm{a}}$ \\
500 & $58.5^{\mathrm{b}}$ & $15.9^{\mathrm{a}}$ & $31.2^{\mathrm{a}}$ \\
1250 & $86.7^{\mathrm{c}}$ & $19.5^{\mathrm{a}}$ & $32.7^{\mathrm{a}}$ \\
\hline
\end{tabular}

Values followed by the same superscript do not differ significantly, at $P=0.01$ and the $\mathrm{CV}=27 \%$.

\section{TABLE 2}

Radioactive ${ }^{45} \mathrm{Ca}$ uptake in DPM by different avocado plant parts with and without TIBA treatment. The $\mathrm{Ca}$ uptake, expressed as a percentage of the available ${ }^{45} \mathrm{Ca}$ in the donor block, is presented in parentheses

\begin{tabular}{|c|c|c|c|}
\hline & \multicolumn{2}{|c|}{13 September 1988} & \multirow{2}{*}{$\frac{21 \text { September } 1988}{0 \text { TIBA }}$} \\
\hline & 0 TIBA & TIBA & \\
\hline Flower panicle & $\begin{array}{l}11303^{c} \\
(24 \%)\end{array}$ & $\begin{array}{c}9413^{d} \\
(20 \%)\end{array}$ & $\mathrm{NA}$ \\
\hline Vegetative flush & $\begin{array}{l}21407^{\mathrm{a}} \\
(47 \%)\end{array}$ & $\begin{array}{l}14220^{\mathrm{b}} \\
(31 \%)\end{array}$ & $\begin{array}{l}16019^{b} \\
(35 \%)\end{array}$ \\
\hline Fruitlet & $\begin{array}{c}8615^{\mathrm{d}} \\
(19 \%)\end{array}$ & $\begin{array}{r}6554^{\mathrm{e}} \\
(14 \%)\end{array}$ & $\begin{array}{c}9672^{\mathrm{d}} \\
(21 \%)\end{array}$ \\
\hline Receiver agar & $\begin{array}{c}215^{f} \\
(0.47 \%)\end{array}$ & $\begin{array}{c}136^{\mathrm{f}} \\
(0.24 \%)\end{array}$ & ND \\
\hline
\end{tabular}

Values followed by the same superscript to not differ significantly at $P=0.01$ and the $\mathrm{CV}=10.8 \%$. $\mathrm{NA}=$ not available; $\mathrm{ND}=$ not determined. 


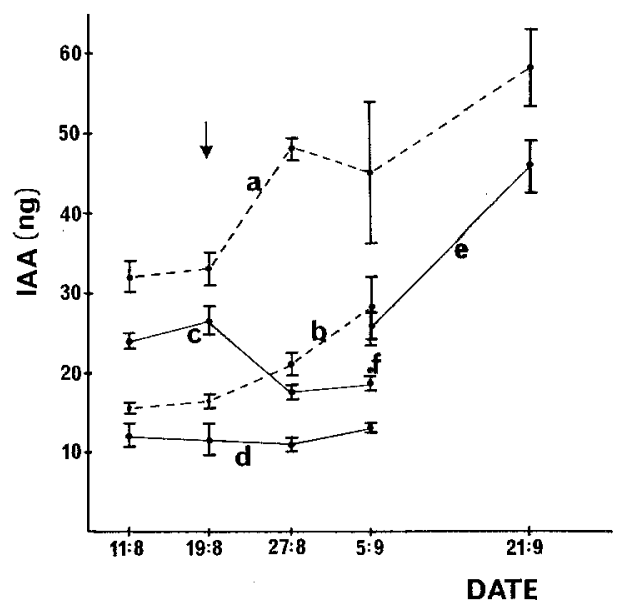

Fig. 3. IAA export from various plant parts: $a=$ vegetative shoots; $b=$ vegetative shoots with TIBA; $c=$ flowers; $d=$ flowers with TIBA; $e=$ young fruits; $f=$ young fruits with TIBA treatment. The arrow indicates maximum flowering. Vertical bars $= \pm \mathrm{SE}$ of the means. Date $=$ day: month.

Auxin transport from reproductive and vegetative growth flushes. - The auxin transport in the expanding vegetative flushes increased from $32 \mathrm{ng}$ to $>55 \mathrm{ng}$ per 10 shoots (Fig. 3, curve a). Auxin transport from the flowers peaked at maximum flower opening and then declined (Fig. 3, curve c). Export of IAA showed an increasing trend with time in young fruitlets (Fig. 3, curve $3 \mathrm{e}$ ). TIBA treatment reduced IAA export from all these organs (Fig. 3 , curves b, d, f).

\section{DISCUSSION}

There is evidence of a strong interaction between $\mathrm{Ca}$ and IAA in plants at the cellular level (Felle, 1988) and findings indicate that a portion of $\mathrm{Ca}^{2+}$ transport in tomato is under the control of fruit-produced IAA (Banuelos et al., 1987). Our results show that a certain proportion of $\mathrm{Ca}$ allocated to the different plant structures appears to be under the control of basipetal auxin movement. This is confirmed by the reduction in Ca uptake in response to the presence of the auxin transport inhibitor, TIBA. Apparently, TIBA did not stop auxin transport completely, but appeared to be more effective when relatively large quantities of auxin were being exported. Care was taken to reduce the transpirational flow to a minimum by maintaining $100 \% \mathrm{RH}$, and as a result reducing the transpiration-dependent $\mathrm{Ca}^{2+}$ import.

Of particular importance was the relative difference in the IAA export strengths of the vegetative and reproductive flushes. Auxin transport is strongly inhibited by a group of ubiquitous phenolic compounds (Jacobs and Rubery, 1988). In avocado, phenolic levels tend to be higher in fruit than those found in vegetative growth (Torres et al., 1987) and this could be at least partly 
responsible for the reduced auxin export from fruitlets relative to the vegetative flush, as found in our study. This area, particularly in the case of fruits which are weak $\mathrm{Ca}$ accumulators, such as avocados, requires further investigation.

In the whole-tree situation, the more vigorous the vegetative flush, the greater the production of IAA (Leopold and Kriedemann, 1975), the stronger the basipetal IAA transport (Banuelos et al., 1987) and the stronger the vegetative sink strength and resultant $\mathrm{Ca}$ allocation. ${ }^{45} \mathrm{Ca}$ uptake was higher in the vegetative flush, but declined with time, while ${ }^{45} \mathrm{Ca}$ uptake into the fruit increased. This was thought to be because of the competitive auxin export which had begun from the young fruits (there being many on a single panicle) (Fig. 3, curve $e$ ) and the observation that although leaf expansion was continuing, no further new leaves were being produced, i.e. apical activity had decreased. Competition between reproductive and vegetative tissue could modify IAA export and dominance phenomena (Bangerth, 1986) and consequently contribute to lower $\mathrm{Ca}^{2+}$ in tissues such as fruit with low transpiration rates.

Our findings show that flowers and, to a lesser extent, young fruits are poor IAA exporters and are weak sinks for non-transpirational $\mathrm{Ca}^{2+}$. This would be to the detriment of potential fruit $\mathrm{Ca}$ allocated under IAA control. This is borne out by $\mathrm{Ca}$ analysis of fruitlets from vigorous and non-vigorous trees, which showed that fruit from non-vigorous 'Fuerte' trees accumulated nearly twice as much $\mathrm{Ca}$ during the first 6 weeks of fruit growth (Whitney et al., 1986), and from observations of a deterioration in post-harvest fruit quality in fruit from very vigorous trees (J.G.M. Cutting, unpublished data, 1988). In South Africa, the soil pathogen Phytophothora cinnamomi has been brought under effective chemical control (Bezuidenhout et al., 1987) resulting in excessive vegetative vigour in avocado trees. The implications of these results are obvious and important as the largest proportion of fruit $\mathrm{Ca}$ is taken up during the first 2 months of fruit growth (Bower, 1985). Therefore, controlling the vigour of the vegetative flush that occurs during and shortly after flowering and fruit set holds potential benefits for the accumulation of fruit $\mathrm{Ca}$ and, as a consequence, better post-harvest quality. Research to reduce vegetative vigour and/or to hold the vegetative flush for 4-6 weeks after flowering is currently receiving attention.

\section{ACKNOWLEDGEMENTS}

J.G.M.C. wishes to acknowledge useful discussion with Prof. F. Bangerth and the excellent technical assistance of Liz Coetzer and Yvette Glass. Drs. J. Robinson and $\mathrm{P}$. Newton are thanked for proofreading the manuscript.

\section{REFERENCES}

Bangerth, F., 1973. Investigations upon Ca-related physiological disorders. Phytopathol. Z., 77: $20-37$. 
Bangerth, F., 1976. A role for auxin and auxin transport inhibitors on the Ca content of artificially induced parthenocarpic fruits. Physiol. Plant., 37: 191-194.

Bangerth, F., 1979. Calcium-related physiological disorders of plants. Annu. Rev. Phytopathol., 17: 97-112.

Bangerth, F., 1986. Thinning of apples and relations to endogenous hormones. Acta Hortic., 179: 605-612.

Banuelos, G.S., Bangerth, F. and Marschner, H., 1987. Relationship between polar basipetal auxin transport and acropetal $\mathrm{Ca}^{2+}$ transport into tomato fruits. Physiol. Plant., 71: 321-327.

Bezuidenhout, J.J., Darvas, J.M. and Toerien, J.C., 1987. Chemical control of Phytophthora cinnamomi. S. Afr. Avocado Grow. Assoc. Yearb., 10: 106-108.

Bower, J.P., 1985. The calcium accumulation pattern in avocado fruit as influenced by long term irrigation regime. S. Afr. Avocado Grow. Assoc. Yearb., 8: 97-99.

Chaplin, G.R. and Scott, K.J., 1980. Association of calcium in chilling injury susceptibility of stored avocados. HortScience, 4: 514-515.

Clarkson, D.T., 1984. Calcium transport between tissues and its distribution in the plant. Plant Cell Environ., 7: 449-456.

Cutting, J.G.M., Hofman, P.J., Lishman, A.W. and Wolstenholme, B.N., 1986. Abscisic acid, isopentenyladenine and isopentenyl adenosine concentrations in ripening fruit as determined by radioimmunoassay. Acta Hortic., 179: 793-800.

Cutting, J.G.M., Bower, J.P. and Wolstenholme, B.N., 1988. Effect of harvest date and applied ABA on polyphenol oxidase levels in avocado (Persea americana Mill.) fruit. J. Hortic. Sci., 63: 509-515.

Eaks, I.L., 1985. Effect of calcium on ripening, respiratory rate, ethylene production and quality of avocado fruit. J. Am. Soc. Hortic. Sci., 110: 145-148.

Felle, H., 1988. Auxin causes oscillations of cytosolic free calcium and $\mathrm{pH}$ in Zea mays coleoptiles. Planta, 174: 495-499.

Hanson, J.B., 1984. The function of $\mathrm{Ca}^{2+}$ in plant nutrition. In: P.B. Tinker and A. Lauchli (Editors), Advances in Plant Nutrition. Vol. 1. Praeger Press, New York, pp. 149-208.

Jacobs, M. and Rubery, P.H., 1988. Naturally occurring auxin transport regulators. Science, 241: 346-349.

Koontz, H.V. and Foote, R.E., 1966. Transpiration and calcium deposition by unifoliate leaves of Phaseolus vulgaris differing in maturity. Physiol. Plant., 19: 313-321.

Leopold, A.C. and Kriedemann, P.E., 1975. Plant Growth and Development. Second Edition. McGraw-Hill, New York, pp. 120-123.

Marschner, H., 1983. Introduction to the mineral nutrition of plants. In: A. Lauchli and R. Bieleski (Editors), Encyclopedia of Plant Physiology, New Series. Vol. 15. Springer Verlag, Berlin, pp. 5-44.

Poovaiah, B.W., 1985. Role of calcium and calmodulin in plant growth and development. Hortic. Sci., 20: 347-352.

Tingwa, P.D. and Young, R.E., 1974. The effect of calcium on the ripening of avocado fruit. J. Am. Soc. Hortic. Sci., 99: 540-542.

Torres, A.M., Mau-Lastovicka, T. and Rezaaiyan, R., 1987. Total phenolics and high performance liquid chromatography of phenolic acids of avocado. J. Agric. Food Chem., 35: 921-925.

Veldman, G., 1983. Kalsiumnitraatbespuitings te Wesfalia op avokados met die doel om pulpvlek te verminder. S. Afr. Avocado Grow. Assoc. Yearb., 6: 64-65.

Weiler, E.W., 1981. Radioimmunoassay for pmol quantities of indole-3-acetic acid for use with highly stable ${ }^{131} \mathrm{I}$ - and ${ }^{3} \mathrm{H}$-IAA derivatives as tracers. Planta, 153: 319-325.

Whitney, G.W., Wolstenholme, B.N. and Hofman, P.J., 1986. Calcium accumulation in avocado fruits: effect of cultivar and tree vigour. S. Afr. Avocado Grow. Assoc. Yearb., 9: 35-38.

Wills, R.B.H. and Tirmazi, S.I.H., 1982. Inhibition of ripening of avocados with calcium. Scientia Hortic., 16: 323-330. 